\title{
Heat Flow into the Tool in Cutting Super Alloy Inconel 718
}

\author{
Thorsten Augspurger, Bingxiao Peng, Fritz Klocke and Benjamin Döbbeler \\ Laboratory for Machine Tools and Production Engineering, RWTH Aachen University, Aachen 52074, Germany
}

\begin{abstract}
Cutting super alloy is a highly sensitive manufacturing process regarding the complex thermo-mechanical interactions in the cutting zone, which finally determine the capability of the process in order to reach economic requirements. The connection between the intensity of heat sources as well as heat partitions into the tool, work piece and chip is yet not fully understood. Thus heat flows and other thermal conditions in the cutting zone cannot be predicted satisfactory, though they influence the chip formation mechanics, the surface integrity, respectively functionality of the machined work piece as well as the tool wear and lifetime. Because of this deficit the ecological and economical design of the manufacturing process is still limited and often not knowledge based. The proposed paper presents a methodology in order to measure and predict heat flows respectively affiliated temperatures during cutting nickel-base super alloy (Inconel 718). The heat flows in the cutting zone are determined by infrared thermography and a further energy balance by post processing the thermal images. A FE-model for chip formation simulation, which is based on CEL (Coupled-Eulerian-Lagrange) formulation, was used to calculate the heat flows. Finally, the results of the simulation and the experiments were compared.
\end{abstract}

Key words: Inconel 718, orthogonal cutting, temperature, heat partition.

\section{State of the Art}

Super alloy Inconel 718 is an important alloy for high temperature applications where oxidation resistance, corrosion resistance and high mechanical strength at elevated temperatures like in aircraft engine parts and steam turbines are required. Its peculiar characteristics such as low thermal conductivity, work hardening, presence of abrasive carbide particles, hardness at elevated temperatures, make in beneficial it the application yet difficult to machine. Thus cost effectiveness and at the same time meeting high quality standards regarding surface integrity and dimensional accuracy are still a challenge [1]. During machining beside the mechanical tool loads especially thermal tool loads and subsequent high temperatures in the cutting zone are observed. The arising temperature fields in the tool lead to wear in different forms of occurrence like adhesion, abrasion, diffusion and comb cracks for interrupted cutting processes due to cyclic heating [2]. From the state of the art

Corresponding author: Thorsten Augspurger, Dipl. Wirt. Ing., research field: manufacturing engineering. estimations of the percentage of heat flowing into the tool the chips and the workpiece differ greatly. Data for the heat input into the tool reach from $1 \%$ to $30 \%$ depending on the parameter setting and cut material [3-6]. Still the predictive models of heat partitions for different manufacturing process depending on the process parameter setting are rare or not available.

On the workpiece side, the process affiliated heat input leads to thermal material stresses and material modifications, which alter the surface and surface layer properties. Finally, the functionality of the part is affected [7].

One way in order to directly resolve heat partitions, is the modeling of the entire temperature field in the cutting zone based on the JAEGER solution [8] for the oblique moving band source. This approach has been advanced and developed by Kommanduri \& HOU [9-11] enabling the modeling of the entire temperature field including tool, workpiece and chip for the stationary orthogonal cutting process under ideal conditions. Result of the model beside the temperature distribution is the heat partitions between the relevant areas in the cutting zone. The model has been 
simplified and adapted for the broaching process by Gierlings [12]. Main disadvantages of the model are its limitation to the stationary state, the two dimensional considerations and the simplified cutting zone consisting of straight lines. Therefore, the direct calculation of the entire temperature distribution only works under idealized conditions and assumptions. In addition, many models only resolve the temperature distribution in defined areas of the cutting zone like tool, workpiece or chip [13-15] and often require a heat source as input variable. "In summary, there is no general agreement on a partition criterion for the heat transfer into the tool, the chip, and the workpiece, in conventional machining. The intensity and distribution of heat sources are extremely difficult to predict in machining operations. This is because the dynamic mechanical and thermal processes are coupled together and influenced each other to a large degree. The elevated temperatures associated with the cutting process significantly alter the material mechanical and thermal properties during the process" [6].

Therefore, a sensible approach would be the separation of the problem into two subtasks namely the solution of the heat partition problem and the subsequent analytical modelling of the temperature fields based of the former calculated heat input in the examined area. In this sense the present paper presents a possible method in order to determine the heat partition into the tool during orthogonal cutting by means of high speed infrared thermography and the application of simple thermodynamic laws.

\section{Empirical Analysis of the Heat Flow into the Tool}

\subsection{Experimental Setup}

The experiments were carried out on an orthogonal cutting machine as shown in Fig. 1. During cutting the tool remained on a fixed position and the workpiece of the dimensions 15.7/17.9 $\times 20 \times 3 \mathrm{~mm}$ (the length varied from workpiece to workpiece) was moved in a linear motion on a hydrostatically mounted carriage.
A purpose-built tool with rake angle $\gamma_{\mathrm{n}}=6^{\circ}$, clearance angle $\alpha_{\mathrm{n}}=12^{\circ}$, cutting edge rounding of $\mathrm{r}_{\beta} \approx$ $5 \mu \mathrm{m}$ consisting of a $10 \%$ Cobalt tungsten carbide (K40UF AFC Hartmetall GmbH \& Co KG) was used. The cutting took place by a tool with a width of 3.4 $\mathrm{mm}$ and approximately $0.1 \mathrm{~mm}$ from the outer rim in order to observe a virtually two-dimensional temperature field without heat diffusion in the lateral direction.

For cutting velocities 35,70 and $140 \mathrm{~m} / \mathrm{min}$ and uncut chip thickness $0 \mu \mathrm{m}$ to $100 \mu \mathrm{m}$ in $10 \mu \mathrm{m}$ steps were chosen. Hitting discrete points regarding the uncut chip thickness was neither possible nor necessary for the actual cut chip thickness was determined subsequently after the cut with the tactile sensor. After each cycle the actual cut chip thickness was measured with a tactile sensor. The process was carried out under dry conditions.

For the force measurement a piezoelectric force platform 9129AA by Kistler was used. It enabled the measurement of the cutting force $F_{\mathrm{c}}$ and the passive force $F_{\mathrm{p}}$ and subsequently the total power in the process. Furthermore, the force platform triggered an infrared camera of the type FLIR SC7600 at a defined signal threshold. Aim of the infrared imaging was to capture the temperature field in the tool before and shortly (duration depending on frame rate) after the cut. The camera had a sensor pitch of $7.5 \mu \mathrm{m}$ at a FOV of $2.6 \times 1.4 \mathrm{~mm}$.

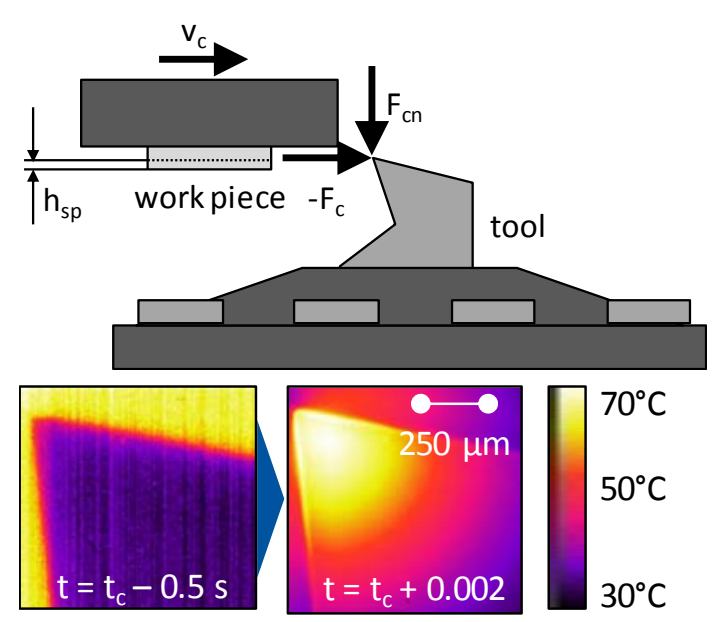

Fig. 1 Orthogonal cutting process. 


\subsection{Post Processing of Thermal Pictures}

The determination of the heat input into the tool by the cutting process was determined by a thermodynamic approach observing the internal energy of the tool before and after cut (see Fig. 1). In this sense the heat input into the tool can be calculated following the first law of thermodynamics by:

$$
\mathrm{Q}_{\text {tool }}=\mathrm{c}_{\mathrm{p}}(\mathrm{T}) \cdot \mathrm{m}_{\text {tool }} \cdot\left(\mathrm{T}_{\text {mean }}-\mathrm{T}_{\mathrm{i}}\right)
$$

with $T_{\text {mean }}$ as the mean temperature inside the tool approximated from observed area of the lateral tool face times the width of cut $w$ and $m_{\text {tool }}$ as the theoretical mass in this volume. Therefore, it was assumed that the temperature field visible on the lateral tool face extends over the depth of cut in order to derive the total heat input. The tool initial temperature $T_{\mathrm{i}}$ was assumed to $20^{\circ} \mathrm{C}$.

The heat capacity $c_{\mathrm{p}}$ was determined by differential scanning calorimetry as nearly constant at $21 \mathrm{~kJ} /(\mathrm{kg} \cdot \mathrm{K})$ in the relevant temperature range. The thermodynamic law in Eq. (1) considers an initial and final state of thermodynamic equilibrium. Thus, the actual course of the process is not of concern. Technically this final thermodynamic equilibrium is not reached in the current process and thus a potential source of error. Neither convectional heat transport nor heat loss by radiation was considered, which seems sensible for the bulk of heat assumed to be transferred by conduction.

\subsection{Heat Load of the Tool in Orthogonal Cutting}

Fig. 2 gives an overview of the resulting thermal loads of the tool for different cutting speeds $v_{\mathrm{c}}$ and uncut chip thickness $h_{\text {sp. }}$. The bottom left diagram shows the heat input into the tool after the cut, which was determined by Eq. (1). The data for $v_{\mathrm{c}}=140$ $\mathrm{m} / \mathrm{min}$ show some scatter. Possible explanations are the high sensitivity and inherent high uncertainty of the measurement principle by means of infrared thermography, where the chosen emissivity (which was fixed here at 1 with black heat resistant paint), radiation from the hot chip, adhesion of material at the cutting edge and other irregularities influence the results of the measurement. In addition, the singular cutting event leads to a high mechanical impact on the cutting edge and instant alteration of its condition in form of chipping, BUE, land wear or other forms of damage with further implications regarding tool contact conditions. In the end one tool was used up to four times due to economic reasons and the influence of tool wear could not be fully excluded. The measurements show the tendency of a rising heat input into the tool $Q_{\text {tool }}$ with decreasing cutting speed and rising uncut chip thickness $h_{\mathrm{sp}}$. The latter observation could be explained by the rising energy release in the primary and secondary shear zone with rising chip thickness and the tendency to sticking friction [16]. The increasing heat input into the tool with decreasing cutting speed may be due to influence of cutting speed on the specific cutting force and the decreased relation between heat diffusivity and heat transportation velocity, which increases the influence of the shear plane heat source on the tool. The heat flow into the tool increases with cutting velocity and uncut chip thickness probably due to the higher heat generation rate.

As can be seen from the plotting in the top left the measured average cutting force $F_{\mathrm{c}}$ over the uncut chip thickness shows a distinct pattern. Based on the measured cutting force $F_{\mathrm{c}}$ and cutting length $l_{\mathrm{c}}$ the total work of the cut was related to the total heat input into the tool in order to derive a heat partition into the tool as can be seen at the top right plot of Fig. 2 . Again the influence of cutting speed can be noticed: The lower the cutting speed the higher is the heat partition into the tool. While in the plot the heat partition into the tool for the cutting velocity $v_{\mathrm{c}}=35$ $\mathrm{m} / \mathrm{min}$ can be clearly separated, the results for higher cutting speeds are more indistinct. The influence of the cutting speed on the heat partition is a long known phenomenon. Possible explanations are the increase of the coulomb friction coefficient with cutting speed 
- $v_{c}=35 \mathrm{~m} / \mathrm{min}\left(I_{c}=15.7 \mathrm{~mm}\right), \bullet v_{c}=70 \mathrm{~m} / \mathrm{min}\left(I_{c}=15.7 \mathrm{~mm}\right)$,

$\circ v_{c}=70 \mathrm{~m} / \mathrm{min}\left(I_{c}=17.9 \mathrm{~mm}\right), \bullet v_{c}=140 \mathrm{~m} / \mathrm{min}\left(I_{c}=15.7 \mathrm{~mm}\right)$,

.. Regression
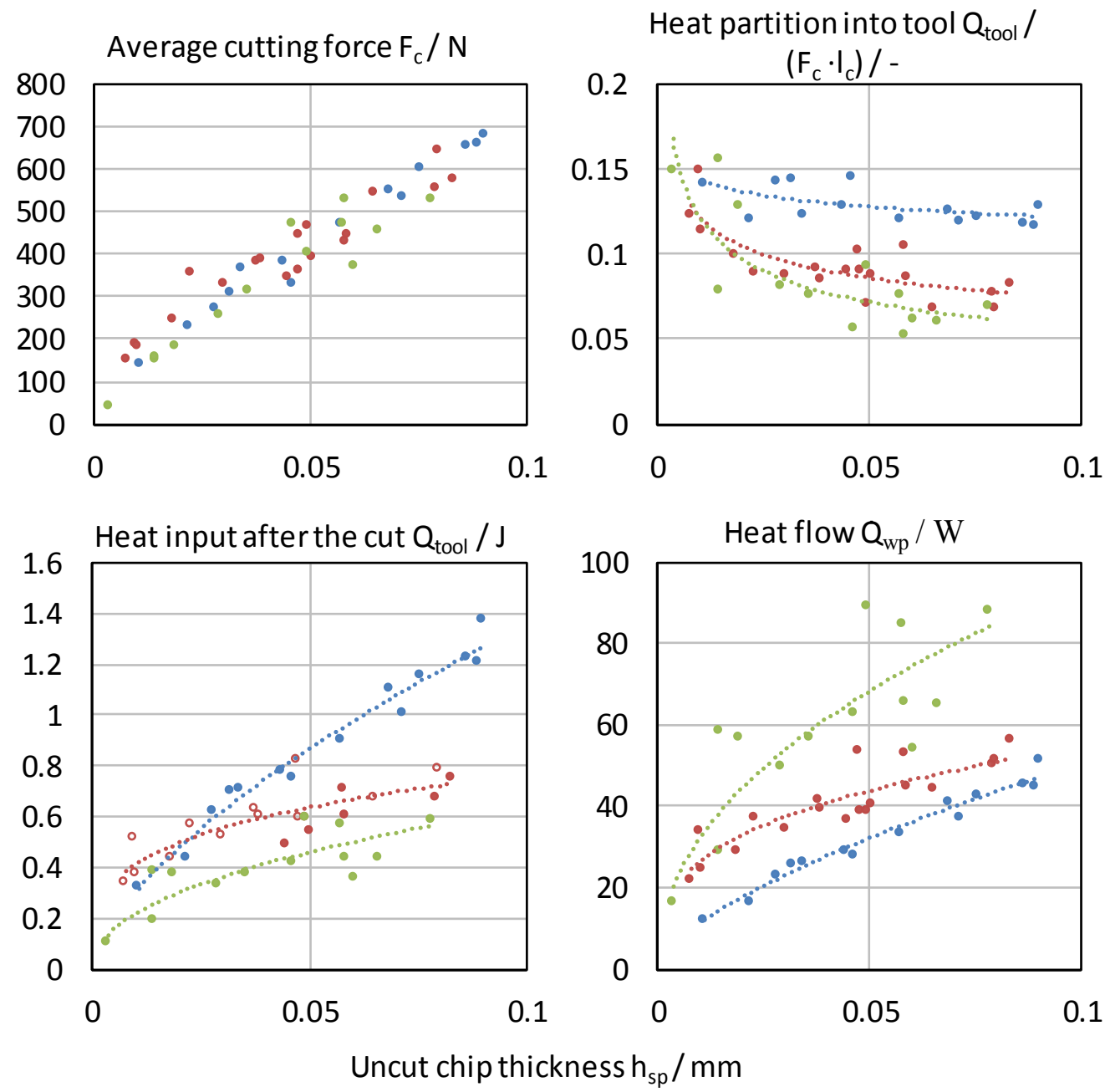

Fig. 2 Measured heat load of the tool.

$[16,17]$, reduced chip-tool contact length [18] or the alteration of heat conduction velocity related to transport velocity summarized under the thermal number [9-11] and a subsequent reduced influence of the heat source in the shear zone on the tool. Thus, the heat transportation velocity increases with cutting speed and subsequently chip velocity. Figuratively spoken: The chip, formed and heated in the shear plane, has not enough time to cool itself down at the rake face. In addition to that the conditions at the rake face shift to sliding friction with increasing cutting velocity and thus decreased heat generation. Fig. 3 shows the calculated heat partition over the affiliated thermal number, a dimensionless variable indicating the relation between advective and conductive heat transportation mechanisms with a possible indication to the heat partition in the process. With rising thermal number, the heat partition into the tool decreases due to the higher influence of the heat transportation velocity. Yet, a prove for the applicability of the thermal number as a heuristic in order to estimate the heat partition into the tool independent from tool material would further require the variation of the material thermal diffusivity, thus a different tool material. 


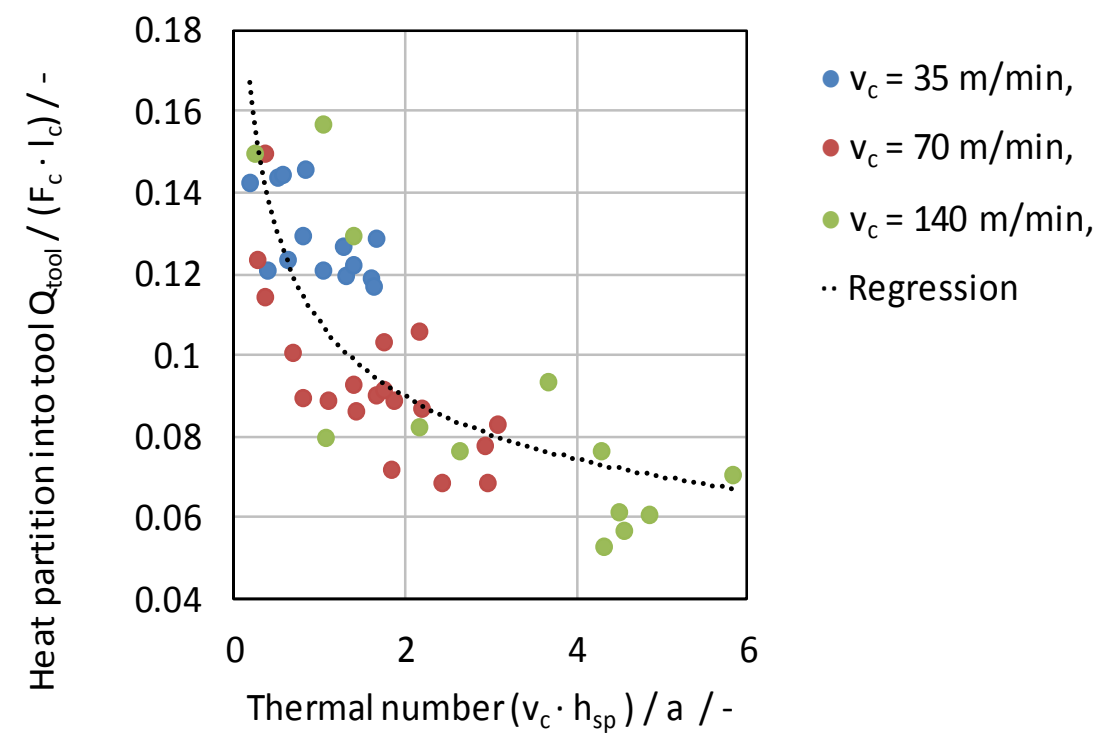

Fig. 3 Heat partition over thermal number.

2.4 FEM-Based Simulations of the Heat Flow into the Tool

In this section the heat flow and heat partition into the tool for the cutting conditions of the experiments are investigated with FEM based simulations.

Based on the work by Puls [19], a 2D FE-model for chip formation of Inconel 718 was modelled with CEL (Coupled-Eulerian-Lagrange) formulation, which enables the fully coupled thermo-mechanical analysis. The FE-model was implemented in ABAQUS Explicit 6.14 and the concept is shown in Fig. 4.

The basic idea of this method is to simulate the cutting process as a continuous flow of work material. This material is then separated into workpiece and chip by the tool which acts as an obstacle. The workpiece and the chip can only stay in the Eulerian domain. In comparison to the lagrangian model, the chip formation with CEL formulation can easily handle the cases with large deformation without remeshing routines. The model is in fact a $3 \mathrm{D}$ model because the CEL method can be only implemented with 3D element EC3D8RT in ABAQUS Explicit, the degree of freedom in z-direction was disabled. The thickness of the element was $20 \mu \mathrm{m}$. In this model, the minimum element size of $2 \mu \mathrm{m}$ was used. To enable the thermal analysis, the element type C3D8RT should be used for tool domain. The tool was defined to be rigid and fixed in this model.

To model the thermal contact without significant resistance, a heat transfer coefficient of $h_{\mathrm{t}}=10,000$ $\mathrm{kW} /\left(\mathrm{m}^{2} \cdot \mathrm{K}\right)$ in tool-chip interface was used. The temperature dependent material properties of carbide were obtained from Ref. [20].

The plastic deformation in shear band is the primary source of the heat generation in cutting process. To describe the plastic material behaviour of Inconel 718, the JC (Johnson-Cook) constitutive model and damage model have been used in this paper. The JC constitutive model describes the dependences of strain $\epsilon$, strain rate $\dot{\epsilon}$ and temperature $T$ on flow stress. The equivalent flow stress $\sigma_{\mathrm{JC}}$ is described by $\mathrm{JC}$ model in Eq. (3). The JC damage model was used in conjunction with JC constitutive model to calculate damage initiation criterion. The failure strain $\epsilon_{\mathrm{f}}$ is described by JC damage model in Eq. (3). According to failure softening theory, once the damage initiation criterion is reached, the flow stress decreases to a lower value. 


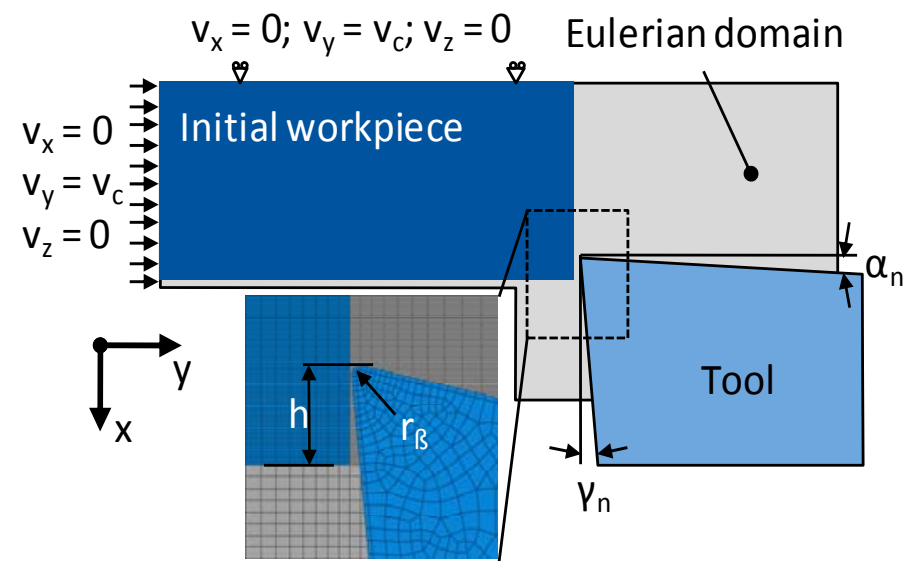

Fig. 4 Concept of coupled Eulerian-Lagrangian model in orthogonal cutting.

Table 1 Johnson-Cook constitutive model parameters for Inconel 718.

\begin{tabular}{llllllll}
\hline $\mathrm{A}[\mathrm{MPa}]$ & $\mathrm{B}[\mathrm{MPa}]$ & $\mathrm{n}$ & $\mathrm{C}$ & $\mathrm{m}$ & $\begin{array}{l}\dot{\varepsilon}_{0} \\
{\left[\mathrm{~s}^{-1}\right]}\end{array}$ & $\begin{array}{l}\mathrm{T}_{\mathrm{m}} \\
{\left[{ }^{\circ} \mathrm{C}\right]}\end{array}$ & $\begin{array}{l}\mathrm{T}_{0} \\
{\left[{ }^{\circ} \mathrm{C}\right]}\end{array}$ \\
\hline 1,200 & 1,284 & 0.54 & 0.006 & 1.2 & 0.001 & 1,800 & 25 \\
\hline
\end{tabular}

Table 2 Johnson-Cook damage model parameters for Inconel 718.

\begin{tabular}{lllll}
\hline $\mathrm{D}_{1}$ & $\mathrm{D}_{2}$ & $\mathrm{D}_{3}$ & $\mathrm{D}_{4}$ & $\mathrm{D}_{5}$ \\
\hline 0.45 & 0.75 & -1.45 & 0.04 & 0.89 \\
\hline
\end{tabular}

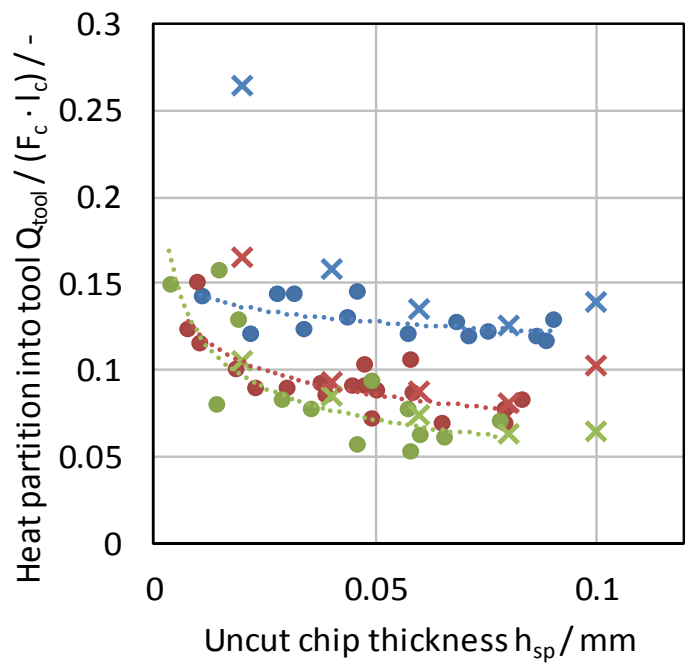

- Meas. $\mathrm{v}_{\mathrm{c}}=35 \mathrm{~m} / \mathrm{min}$,

- Meas. $\mathrm{v}_{\mathrm{c}}=70 \mathrm{~m} / \mathrm{min}$,

- Meas. $\mathrm{v}_{\mathrm{c}}=140 \mathrm{~m} / \mathrm{min}$,

$\times \operatorname{Sim} . \mathrm{v}_{\mathrm{c}}=35 \mathrm{~m} / \mathrm{min}$,

$\times$ Sim. $v_{c}=70 \mathrm{~m} / \mathrm{min}$,

Sim. $v_{c}=140 \mathrm{~m} / \mathrm{min}$,

. Regression meas.,

- Regression sim.

Fig. 5 Comparison of heat partition into the tool between experiments and FE-simulations.

The JC constitutive and damage model parameters of Inconel 718 have already been determined by previous works and are shown in Tables 1 and 2 .

$$
\begin{aligned}
& \sigma_{J C}=\left(A+B \cdot \varepsilon^{n}\right) \cdot\left(1+C \cdot \ln \frac{\dot{\varepsilon}}{\dot{\varepsilon}_{0}}\right) \\
& \cdot\left(1-\left(\frac{T-T_{0}}{T_{m}-T_{0}}\right)^{m}\right)
\end{aligned}
$$

$$
\begin{gathered}
\varepsilon_{f}=\left(D_{1}+D_{2} \cdot \varepsilon^{D_{3} \cdot \eta}\right) \cdot\left(1+D_{4} \cdot \ln \frac{\dot{\varepsilon}}{\dot{\varepsilon}_{0}}\right) \\
\cdot\left(1-D_{5} \cdot \frac{T-T_{0}}{T_{m}-T_{0}}\right)
\end{gathered}
$$

The friction at the tool-chip interface is another source of heat generation. Friction model has significant influence on cutting process simulation. 
According to the investigations by previous researchers, the friction coefficient decreases with increasing relative cutting velocity [18].

For this reason, the tool-chip interface was modelled by a temperature dependent friction model in this paper. It can be explained by temperature softening with high cutting velocity. The temperature dependent friction coefficients between Inconel 718 and uncoated carbide (H13A) were experimental investigated under different cutting conditions by an advanced test bench [21]. The convection of tool and workpiece as well as the chip to environment was not modelled in this paper.

To reduce the computing time, all the simulations were running $1.2 \mathrm{~ms}$, when the cutting forces have reached quasi-steady state. The FE-simulations ran 1.2 ms to obtain the stable chip formation. The transient heat flows $\dot{Q}_{\text {tool }}(0-1.2 \mathrm{~ms})$ into the tool were calculated from the simulations by derivation of the internal energy of the cutting tools. Subsequently the heat flow $\dot{\mathrm{Q}}_{\text {tool }}$ during the cutting in the time point 2 ms (steady state reached) was predicted by a logarithmic regression of the transient heat flow. In Fig. 5 a comparison of the predicted heat partition into the tool between the experiments and the simulations is shown with qualitatively and quantitatively good agreement.

\section{Conclusions and Future Works}

Two approaches in order to estimate the heat partition into the tool in orthogonal cutting were conducted and compared. While the simulation was not restricted to the heat flow into the tool and enabled a heat partition for the entire cutting zone, it required model parameters for the investigated materials. The proposed direct method in order to measure the heat flow is restricted to the tool and cannot resolve the entire heat partition. Still it is independent from any material related data input and thus enables an easy approach to estimate the heat flow conducted into the tool. The future work shall improve the method in order to determine the heat partition in particular with regard to the heat flow into the chip and the work piece.

\section{Acknowledgements}

The authors wish to thank the German Research Foundation (DFG) for funding the transregional Collaborative Research Center SFB/TR 96 "Thermo-Energetische Gestaltung von Werkzeugmaschinen" (Aachen, Chemnitz, Dresden), subproject A02.

\section{References}

[1] Thakur, D. 2009. "Study on the Machinability Characteristics of Super-Alloy Inconel 718 during High Speed Turning." Materials and Design 30 (5): 1718-25.

[2] Klocke, F. 2011. Manufacturing Processes 1. Berlin: Springer-Verlag.

[3] Tönshoff, H. K., and Denkena, B. 2004. Spanen: Grundlagen. Berlin: Springer-Verlag.

[4] Pabst, R., Fleischer, J., and Michna, J. 2010. "Modelling of the Heat Input for Face Milling Processes." CIPR Annals 59 (1): 121-4.

[5] Umbrello, D., Filice, L., Rizzuti, S., Micari, F., and Settineri, L. 2007. "On the Effectiveness of Finite Element Simulation of Orthogonal Cutting with Particular Reference to Temperature Prediction.” Journal of Material Processing Technology 189 (1): 284-91.

[6] Abukhshim, N., Mativenga, P., and Sheikh, M. A. 2006. "Heat Generation and Temperature Prediction in Metal Cutting: A Review and Implications for High Speed Machining." International Journal of Machine Tools \& Manufacture 46 (7-8): 782-800.

[7] Brinksmeier, E., Gläbe, R., Klocke, F., and Lucca, D. A. 2011. "Process Signatures-An Alternative Approach to Predict Functional Workpiece Properties." Procedia Engineering 19: 44-52.

[8] Jaeger, J. C. 1942. "Moving Sources of Heat and the Temperatures at Sliding Contacts." Journal and Proceedings of Royal Society of New 76: 203-24.

[9] Komanduri, R., and HOU, Z. B. 2000. "Thermal Modeling of the Metal Cutting Process-Part I: Temperature Rise Distribution due to Shear Plane Heat Source." International Journal of Mechanical Sciences 42 (9): 1715-52.

[10] Komanduri, R., and HOU, Z. B. 2001. "Thermal Modeling of the Metal Cutting Process-Part II: Temperature Rise Distribution due to Frictional Heat 
Source at the Tool-Chip Interface." International Journal of Mechanical Sciences 43 (1):57-88.

[11] Komanduri, R., and HOU, Z. B. 2001. "Thermal Modeling of the Metal Cutting Process-Part III: Temperature Rise Distribution due to the Combined Effects of Shear Plane Heat Source and the Tool-Chip Interface Frictional Heat Source.” International Journal of Mechanical Sciences 43 (1): 89-107.

[12] Klocke, F., Gierlings, S., Veselovac, D., and Brockmann, M. 2014. "Force-Based Temperature Modeling for Surface Integrity Prediction in Broaching Nickel-Based Alloy." In Proceedings of CIRP Conference on Surface Integrity, 314-9.

[13] Stephenson, D. A., and Ali, A. 1992. "Tool Temperatures in Interrupted Metal Cutting." Journal of Engineering for Industry 114 (2): 127-36.

[14] Klocke, F., Gierlings, S., Veselovac, D., and Brockmann, M. 2015. "Analytical Model of Temperature Distribution in Metal Cutting Based on Potential Theory." Mechanical Sciences 6: 89-94.

[15] Brockmann, M. 2015. On the Use of Potential Theory for
Thermal Modelling in Metal Cutting. Aachen: Apprimus Verlag.

[16] Abouridouande, M., Lung, D., Veselovac, D., and Klocke, F. 2015. "The Mechanics of Cutting: In-situ Measurement and Modelling." Procedia CIRP 31: 246-51.

[17] Trent, E. M. 1988. "Metal Cutting and the Tribology of Seizure: I-Seizure in Metal Cutting." Wear 128: 29-45.

[18] Rech, J., Arrazola, P. J., Claudin, C., Courbon, C., Pusavec, F., and Kopac, J. 2013. "Characterisation of Friction and Heat Partition Coefficients at the Tool-Work Material Interface in Cutting." CIRP Annals-Manufacturing Technology 62 (1): 79-82.

[19] Puls, H. 2015. Mehrskalenmodellierung thermo-elastischer Werkstückdeformationen beim Trockendrehen. Aachen: Apprimus Verlag.

[20] Spriggs, G. E. 2002. 13.4 Properties of Hardmetals and Cermets. Edited by Beiss, P., Ruthardt, R., and Warlimont, H. Berlin: Springer-Verlag.

[21] Puls, H., Klocke, F., and Lung, D. 2014. "Experimental Investigation on Friction under Metal Cutting Conditions." Wear 310 (1-2): 63-71. 